\title{
The detection of myoglobin in urine and its distinction from normal and variant haemoglobins
}

\author{
F. E. BOULTON AND R. G. HUNTSMAN \\ From the Department of Haematology, St. Thomas' Hospital Medical School, London
}

SYNOPSIS Victims of severe injuries frequently pass haemoglobin, myoglobin, or both proteins in their urine. If the kidneys of such persons are to be considered as donor material for transplantation, a pathology department may be requested to identify which of these pigments is present. If freshly passed urine is available, haemoglobinuria in the absence of myoglobinuria may be rapidly identified by spectroscopy. However, the rapid degradation of myoglobin to the met-myoglobin form will make spectroscopic recognition of this pigment in the urine unreliable. In the absence of variant haemoglobins, myoglobin may be easily distinguished from normal haemoglobin by routine electrophoresis on paper, starch gel, or cellulose acetate at alkaline $p \mathrm{H}$. The electrophoretic method of choice in the presence of variant haemoglobins utilizes polyacrylamide gel at $12 \mathrm{~g} / 100 \mathrm{ml}$ as a supporting medium. At this concentration, the migration both of haemoglobin and its variants is sufficiently retarded to allow the easy recognition of myoglobin.

During a survey to assess the frequency of variants of human myoglobin, it was necessary to use as a source material aqueous extracts of muscle in which variable quantities of both haemoglobin and myoglobin were always present. Techniques were therefore developed to detect myoglobin and its variants in the presence of haemoglobin. On a number of occasions, it was necessary to distinguish haemoglobin variants from myoglobin.

Experience gained by examining 6,000 muscle samples (Boulton, Huntsman, Yawson, Romero Herrera, Lorkin, and Lehmann, 1971) has been utilized for the identification of haemoglobin in several specimens of haemoglobinuria and of myoglobin in one specimen of myoglobinuria.

\section{Materials and Methods}

Urine from the following cases were examined:

Cases 1 and 2 were patients with haemoglobinuria resulting from open heart surgery (aortic valve replacement) during which the circulation was maintained extracorporeally.

Case 3 was a 70-year-old man with cold-antibody haemolytic anaemia and haemoglobinuria.

Case 4 was a 17-year-old youth, involved in a road traffic accident, who sustained fatal crushing injuries. Haemoglobin was identified in his urine

Received for publication 25 March 1971. after transfusion. His kidneys were successfully transplanted into two anephric recipients.

Case 5 was a 20 -year-old youth with intermittent myoglobinuria, usually following exercise.

Wherever possible, the tests were carried out on freshly passed urine; when storage was required, it was found that freezing and thawing the urine precipitated much of the myoglobin. All specimens were stored at $+4^{\circ} \mathrm{C}$ and, under these conditions, haemoglobin is oxidized over several days to ferrihaemoglobin. Myoglobin is converted to ferrimyoglobin more rapidly; indeed some may be already oxidized in freshly passed urine (Whisnant, Owings, Cantrell, and Cooper, 1959).

On occasion, it was necessary to concentrate the urine. This is most conveniently carried out by dialysis against Carbowax, a procedure which does not interfere with the electrophoretic properties of either myoglobin or haemoglobin.

The following methods were employed:

1 The spectroscopic characteristics of the urine and control solutions were determined on a Unicam SP800 A ultraviolet recording spectrophotometer.

Reduction of the haem proteins was produced by $\stackrel{\circ}{\subset}$ adding small quantities of sodium dithionite to the solutions. In the case of myoglobin, extreme care was found to be necessary because the myoglobin was easily precipitated by excess dithionite. A more $\frac{D}{D}$ 'physiological' reduction of ferrimyoglobin was $\frac{?}{\mathbb{D}}$ achieved by adding $\beta$ NADH and diaphorase in 
molar proportions, at $p \mathrm{H} \mathrm{7.5.} \mathrm{The} \mathrm{reaction} \mathrm{was}$ carried out in an evacuated flask and was completed after 90 minutes at $30^{\circ} \mathrm{C}$.

The carbon-monoxy derivatives were prepared by exposing solutions of the ferroproteins to coal gas.

2 Ultrafiltration at atmospheric pressure was performed through Visking tubing $8 / 32$ in. diameter (Craig, King, and Stracher, 1957; Boyer, Fainer, and Naughton, 1963) by the application of an external vacuum.

3 Salt fractionation was carried out according to the method of Blondheim, Margoliash, and Shafrir (1958). After confirming the protein nature of the pigment by precipitating it with sulphosalicyclic acid, $2.8 \mathrm{~g}$ of ammonium sulphate was added to $5 \mathrm{ml}$ of the pigmented urine.

4 Electrophoresis was carried out on paper using Tris buffer $p \mathrm{H} 8.9$ (Cradock-Watson, Fenton, and Lehmann, 1959) and on cellulose acetate (Graham and Grunbaum, 1963). Both these techniques require prior concentration of the urine.

5 Acrylamide gel disc electrophoresis (Ornstein, 1964) was performed using two concentrations of acrylamide monomer: (a) the commonly recommended concentration of $7 \mathrm{~g} / 100 \mathrm{ml}$ of final gel, and (b) a concentration of $12 \mathrm{~g} / 100 \mathrm{ml}$ of final gel. For both, the same buffer system was used, namely, $0.09 \mathrm{M}$ Tris glycine buffer at $p \mathrm{H} \mathrm{9.5}$. The gel tubes were $65 \mathrm{~mm}$ long by $5 \mathrm{~mm}$ diameter, containing $1 \cdot 1 \mathrm{ml}$ of gel and were supported vertically between two electrolyte tanks. Ammonium persulphate was used as catalyst. A current of 60 volt (about $1 \frac{1}{2} \mathrm{~m}$ amp per tube) was passed for one hour. Solutions containing more than $20 \mathrm{mg}$ of haem protein per $100 \mathrm{ml}$ may be applied neat.

6 Isoelectric focusing was carried out after the method of Wrigley (1968) in tubes similar to those used for acrylamide gel electrophoresis, with a supporting gel of $7 \mathrm{~g}$ acrylamide $/ 100 \mathrm{ml}$. The stock solution of $40 \%$ carrier ampholyte mixture $(p H$ range 7-10) was diluted to $2 \%$ in the final gel. Ammonium persulphate was used as catalyst. Neat urine, $0.5 \mathrm{ml}$, or a control sample containing about $20 \mathrm{mg} / 100 \mathrm{ml}$ of haem protein, was mixed into the gel before setting. Orthophosphoric acid $2.5 \%$ was used in the anodal (upper) tank, and $5 \%$ ethanolamine in the cathodal (lower) tank.

\section{CONTROL SOLUTIONS}

Normal human myoglobin, partially purified by ultrafiltration, was obtained from a crude extract of fresh psoas muscle taken at necropsy. Concentrating the ultrafiltrate by dialysis against Carbowax or sucrose granules resulted in a control sample suitable for electrophc retic procedures, but the inevitable presence of some ferrimyoglobin in these control samples necessitated chemical reduction before spectroscopic studies could be performed.

Normal adult human haemoglobin ( $\mathrm{Hb} \mathrm{A}$ ) was prepared by lysing freshly washed red cells.

\section{Results}

\section{SPECTROSCOPY}

A solution of oxyhaemoglobin in fresh urine (or plasma) was found to have spectral properties identical to those of a fresh haemolysate, with peaks at $542 \mathrm{~nm}$ and $577 \mathrm{~nm}$, which in turn is readily distinguished from oxymyoglobin with peaks at $544 \mathrm{~nm}$ and $581 \mathrm{~nm}$ (Fig. 1). Unfortunately, the oxidation of

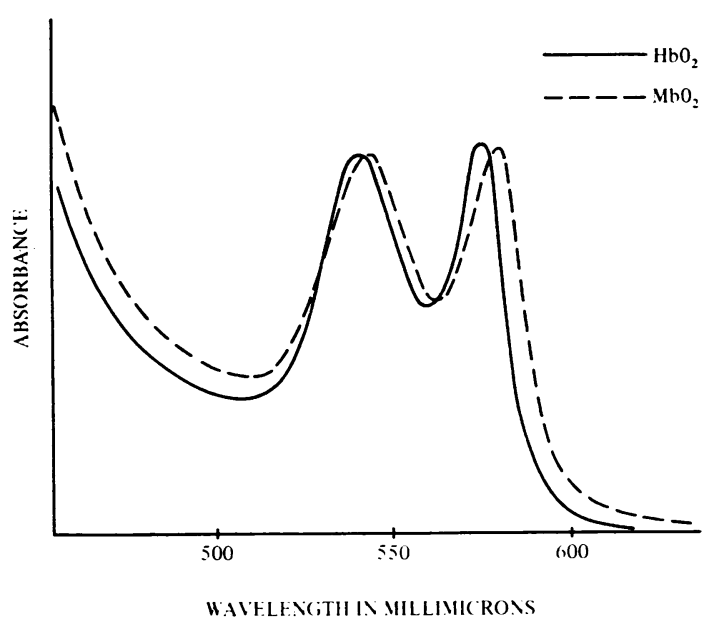

Fig. 1 Absorption curves of oxyhaemoglobin and oxymyoglobin. The oxyhaemoglobin absorption peaks at $542 \mathrm{~nm}$ and $577 \mathrm{~nm}$ permit differentiation from oxymyoglobin, which has absorption peaks at $544 \mathrm{~nm}$ and $581 \mathrm{~nm}$.

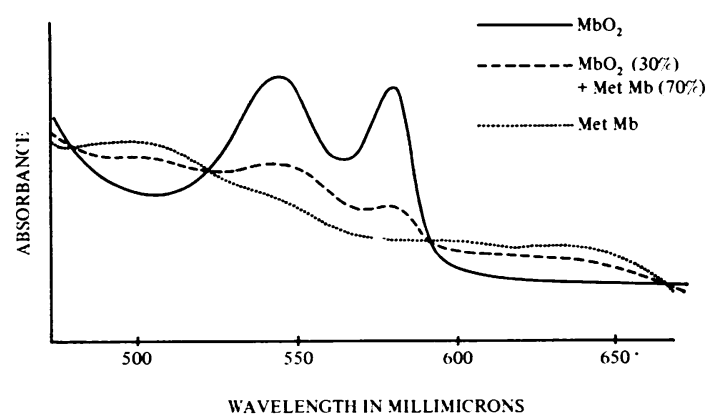

Fig. 2 Absorption curves at pH 7.5 of oxymyoglobin, met-myoglobin, and a mixture of oxymyoglobin and met-myoglobin. 


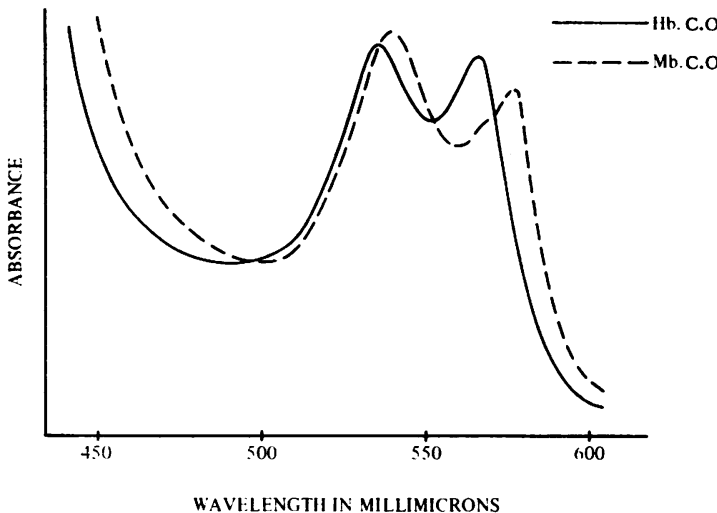

Fig. 3 Absorption curves of carbonmonoxyhaemoglobin and carbonmonoxymyoglobin. The marked difference in the a peak of carbonmonoxyhaemoglobin $(568 \mathrm{~nm})$ and carbonmonoxymyoglobin $(578 \mathrm{~nm})$ permits easy differentiation between these two pigments.

myoglobin to ferrimyoglobin may prevent the positive identification of this pigment in untreated urine (Fig. 2). There is a marked difference in the spectroscopic properties of the carbon monoxy piagments, the $\alpha$ peaks of myoglobin being at 578 $\mathrm{nm}$ and that of haemoglobin at $568 \mathrm{~nm}$ (Fig. 3).

\section{ULTRAFILTRATION}

Myoglobin in urine was found to pass through the membrane with ease, and was recognized by its pink colour and positive peroxidase activity. Haemoglobin does not pass through the membrane.
SALT FRACTIONATION

All samples, including the sample with myoglobinuria, were found to yield a precipitate of haem-protein.

\section{ELECTROPHORESIS}

Using both paper and cellulose acetate electrophoresis (Fig. 4), myoglobin was found to move just cathodally to sickle haemoglobin (Hb S) but in practice the two pigments could not be distinguished. Myoglobin excreted in the urine was found to have exactly the same mobility as freshly prepared myoglobin from muscle. However, haemoglobin excreted into the urine always presented, either partly or wholly, a band anodal to the prepared control haemoglobin.

\section{ACRYLAMIDE GEL DISC ELECTROPHORESIS}

At $7 \mathrm{~g}$ of acrylamide monomer per $100 \mathrm{ml}$ of gel, haemoglobin and myoglobin were found to have comparable electrophoretic mobilities.

At $12 \mathrm{~g}$ of acrylamide monomer per $100 \mathrm{ml}$ of gel, myoglobin was easily distinguished from haemoglobin. However, at this concentration of acrylamide the variants of haemoglobin separate from each other poorly, only those variants with a double change of molecular charge, such as $\mathrm{Hb}$ I High Wycombe $\beta 59$ (E3) Lys $\rightarrow$ Glu (Boulton, Huntsman, Lehmann, Lorkin, and Romero-Herrera, 1970) separating as a distinct band from $\mathrm{Hb} \mathrm{A}$. But even this rare haemoglobin, which moves anodally to $\mathrm{Hb} \mathbf{A}$, is still distinguishable from myoglobin.

Figure 5 illustrates these results.

ISOELECTRIC FOCUSING

Isoelectric focusing permits the differentiation of

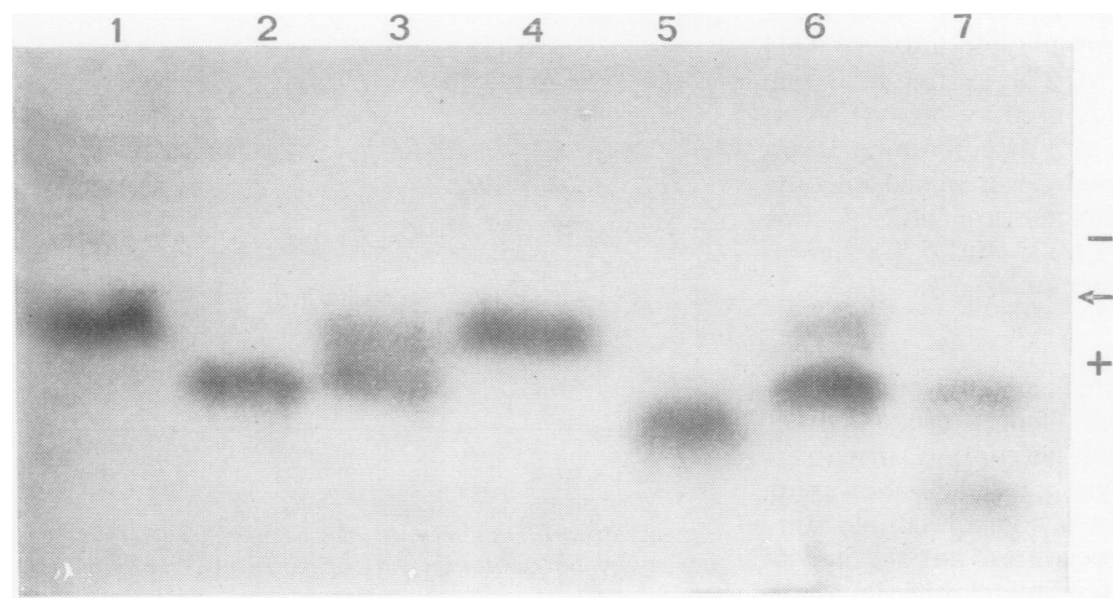

Fig. 4 Electrophoresis on paper at $\mathrm{pH}$ 8.9: (1) pure myoglobin; (2) haemoglobin from normal blood; (3) haemoglobin from blood heterozygous for $\mathrm{Hb} \mathrm{A}$ and $\mathrm{S}$; (4) urine from a case of myoglobinuria; (5) urine from a case of haemoglobinuria; (6) a mixture of normal haemoglobin and myoglobin; (7) haemoglobin from blood heterozygous for $\mathrm{Hb} \mathrm{A}$ and $\mathrm{Hb} \mathrm{I}$. 


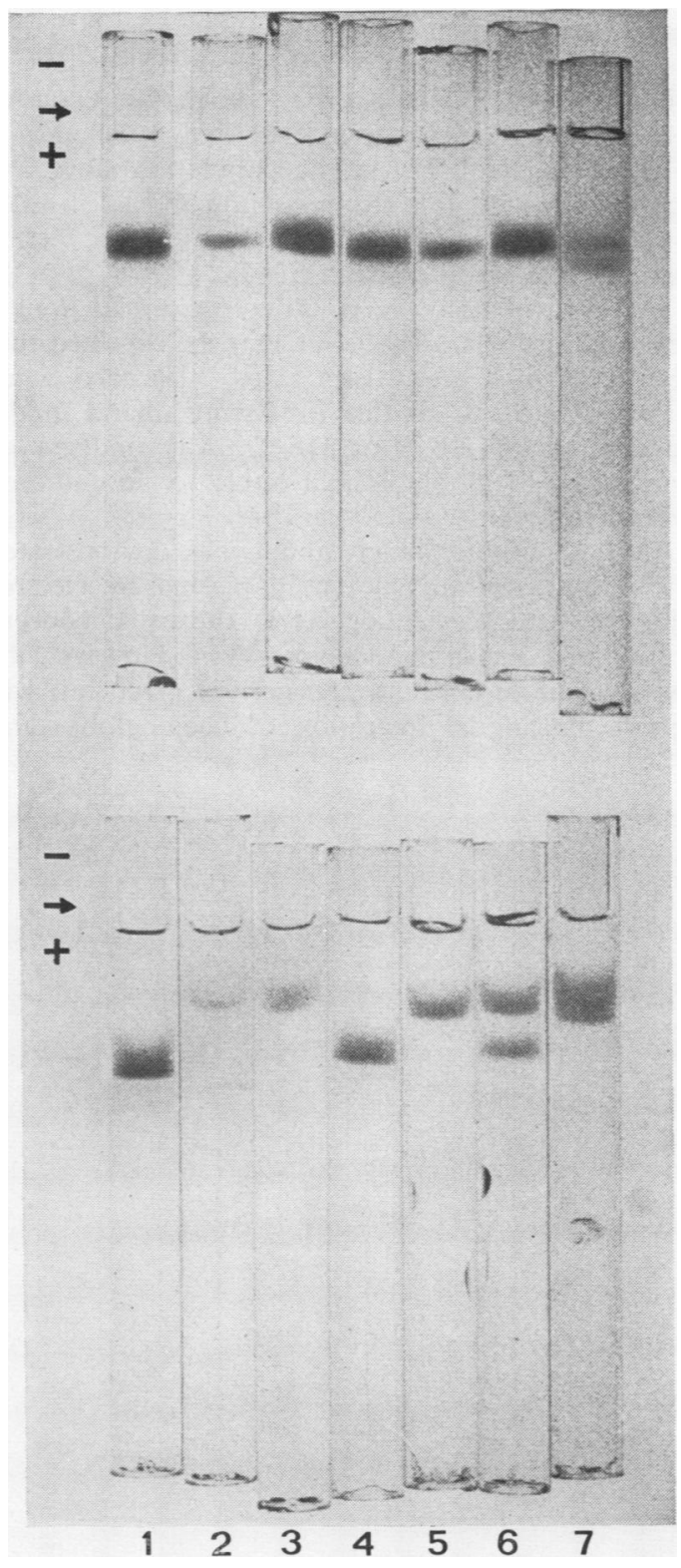

Fig. 5 Disc electrophoresis in acrylamide gel at $\mathrm{pH}$ 9.5. Method as described in text. The tubes in the upper row contain $7 \mathrm{~g}$ of acrylamide monomer per $100 \mathrm{ml}$ of gel and those in the lower row $12 \mathrm{~g} \mathrm{per}$ $100 \mathrm{ml}$ of gel. Samples from left to right. (1) pure myoglobin; (2) haemoglobin from normal blood; (3) haemoglobin from blood heterozygous for $\mathrm{Hb} \mathrm{A}$ and $\mathrm{Hb} S$; (4) urine from a case of myoglobinuria; (5) urine from a case of haemoglobinuria; (6) a mixture of normal haemoglobin and myoglobin; (7) haemoglobin from blood heterozygous for $\mathrm{Hb} \mathrm{A}$ and $\mathrm{Hb} \mathrm{I}$. normal myoglobin from both normal haemoglobin and sickle-cell haemoglobin. With this technique, $\mathrm{Hb} \mathrm{I}$ is found in an identical position to normal myoglobin.

\section{Discussion}

Thomas (1968) gives the following as the main causes of myoglobinuria: muscle damage by crushing, infarction, or electric shock, acute polymyositis, McArdle's syndrome (McArdle, 1951), and adolescent and childhood forms of idiopathic myoglobinuria. The childhood form is usually provoked by infections, and the adolescent form by hard exercise.

Persons sustaining severe muscular injuries, perhaps with blood loss necessitating transfusion, may present with haemoglobinuria, myoglobinuria, or both. The kidneys of such patients may be transplanted and the influence of a preexisting haemoglobinuria or myoglobinuria on survival of the graft has yet to be assessed. Under these circumstances it is desirable to identify the haem pigment present in the urine correctly.

Myoglobin rarely reaches levels in the plasma high enough to cause significant colouration as it is excreted by the kidneys rapidly, whereas binding of haemoglobin by haptoglobin usually colours the plasma distinctly pink before free haemoglobinuria ensues. Hence, if available, inspection of plasma taken during pigmenturia may offer a rapid guide of the type of haem pigment present (Duma, Trigg, and Hammack, 1962).

Elek and Anderson (1953) distinguished clearly between oxymyoglobin and oxyhaemoglobin by spectroscopy (Fig. 1) and in 1955, Berenbaum, Birch, and Moreland demonstrated the even greater spectroscopic differences between their carbon monoxy derivatives (Fig. 3).

In practice, oxyhaemoglobin in fresh urine is relatively stable and has identical spectral characteristics to normal oxyhaemoglobin. It may therefore be identified by routine spectrophotometry, so long as myoglobin is not also present. In contrast the detection of the less common myoglobinuria by spectroscopy is not so reliable because oxymyoglobin is easily oxidized to ferrimyoglobin (Fig. 2). Although it is possible to convert ferrimyoglobin either to oxymyoglobin or to carboxymyoglobin before spectroscopic examination, it is found that chemical reduction may result in denaturation of the protein. Unfortunately the easily prepared and stable cyanmet forms have virtually identical spectra. It is of interest that Duma et al (1962) did not recommend the differentiation of haemoglobin or myoglobin by spectroscopic examination of urine. 
Ultrafiltration as described here is a simple but lengthy procedure. Unfortunately we have found that visual assessment of the ultrafiltrate may be confusing due to the presence of urochromes. Also, testing the filtrate for peroxidase activity may be unreliable because the urine was found, on several occasions, to inhibit the peroxidase activity of a control solution of haemoglobin. The separation of myoglobin and haemoglobin by the 'molecular sieve' action of Sephadex (Awad, Cameron, and Kotite, 1963) depends, like ultrafiltration, on the different sizes of the two molecules.

In our experience, the ammonium sulphate fractionation of Blondheim et al (1958) is unreliable; in this we agree with Duma et al (1962). However, this technique is still in use in many clinical laboratories.

Fletcher and Prankerd (1955) and also Prankerd (1956) demonstrated that myoglobin and haemoglobin possessed different electrophoretic mobilities. Duma et al (1962) reviewed several techniques for differentiating myoglobin from haemoglobin and recommended electrophoresis on paper with $0.05 \mathrm{M}$ veronal buffer at $p \mathrm{H} \mathrm{8.6.}$

Myoglobin travels cathodally to haemoglobin when electrophoresed at alkaline $p \mathrm{H}$ on the standard media such as paper, starch gel, or cellulose acetate. Urinary haemoglobin from cases of haemoglobınuria gives an electrophoretic band anodal to the band of normal haemoglobin (Fig. 4). This is because haemoglobin in the urine is partially or completely degraded by carboxypeptidase $B$ activity while passing through the plasma. This removes the $\alpha$ terminal arginine residues (Marti, Beale, and Lehmann, 1967). As myoglobin is not susceptible to carboxypeptidase B, the electrophoretic mobility of myoglobin passed into the urine is unchanged from that of normal myoglobin, and is easily distinguished from both normal haemoglobin and its degraded form.

If the patient possesses a positively charged variant of haemoglobin, such as sickle haemoglobin (Hb S) or haemoglobin D, the electrophoretic position of the variant band on standard media may coincide with that of normal myoglobin. Therefore, unless the presence of variant haemoglobins in the blood of the patient has been excluded, examination of the urine in cases of haemoglobinuria by simple electrophoretic techniques may be misleading, reporting the presence of myoglobin and haemoglobin (if the subject is heterozygous as in the sicklecell or $\mathrm{Hb} \mathrm{D}$ trait) or even myoglobin alone (if the subject is homozygous as in sickle-cell anaemia or $\mathrm{Hb} \mathrm{D}$ disease), or doubly heterozygous as in sickle cell haemoglobin $\mathrm{D}$ disease.

These two common variants are carried by millions of people. $\mathrm{Hb} \mathrm{S}$ is found predominantly in negroes, being present in up to $20 \%$ of the population of central Africa (Allison, 1965) and in between 5 and $10 \%$ of West Indians (Jonxis, 1965). The common Hb D variant is centred on the Punjab where it is present in about $2 \%$ of the population (Bird and Lehmann, 1956). It is also present in about 1 in 1,000 of the native English and Irish (Konigsberg, Huntsman, Wadia, and Lehmann, 1965).

As both of these variants have terminal arginyl residues on their $\alpha$ chains, it is to be expected that they may also be at least partly degraded when passed into the urine, thus producing a band anodal to controls of $\mathrm{Hb} \mathrm{S}$ or $\mathrm{Hb} \mathrm{D}$. Any undegraded variant haemoglobin is still liable to be confused with myoglobin.

In 1967, Eliot, Shafer, and Gibas demonstrated the presence of myoglobin in plasma by electrophoresis with acrylamide gel at the usual concentration of $7.2 \mathrm{~g}$ acrylamide per $100 \mathrm{ml}$. However, the use of a more concentrated gel $(12 \mathrm{~g} / 100 \mathrm{ml})$ will retard the anodal migration of haemoglobin and

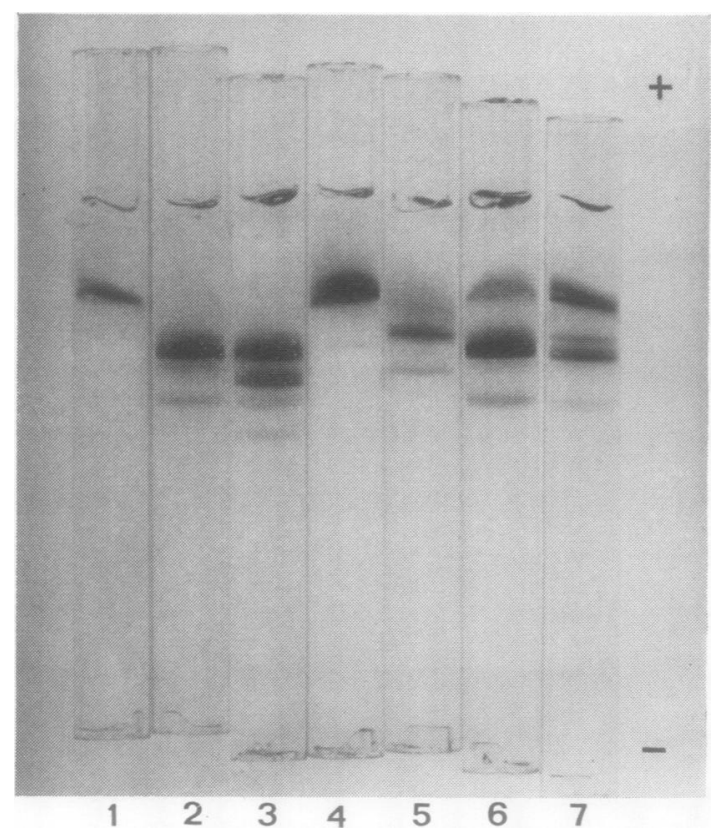

Fig. 6 Isoelectric focusing in acrylamide gel. Method as described in text. Samples from left to right: (1) pure myoglobin; (2) haemoglobin from normal blood; (3) haemoglobin from blood heterozygous for $\mathrm{Hb} \mathrm{A}$ and $\mathrm{Hb} S$; (4) urine from a case of myoglobinuria; (5) urine from a case of haemoglobinuria; (6) a mixture of normal haemoglobin and myoglobin; (7) haemoglobin from blood heterozygous for $\mathrm{Hb} \mathrm{A}$ and $\mathrm{Hb} \mathrm{I}$. A minor fraction is seen to accompany each major fraction of haemoglobin. The nature of these has not been determined. 
permit myoglobin to be differentiated from both normal and variant haemoglobins with ease (Fig. 5). This technique appears to be the method of choice for the examination of the urine of a patient known to carry a haemoglobin variant.

Isoelectric focusing as described here is as easy a technique as that of acrylamide gel disc electrophoresis. The resulting bands become increasingly crisp up to about two hours of current flow. This effect highlights the presence of the minor fractions of myoglobin (Vesterberg, 1967) and also the presence of haemoglobin $A_{2}$ in haemolysates of normal blood. However, we feel that the separation of the variants of haemoglobin, which is very much wider than that achieved by polyacrylamide gel at $12 \mathrm{~g} / 100 \mathrm{ml}$, is, in this context, disadvantageous as negatively charged variants of haemoglobin may be sufficiently close to myoglobin to cause confusion (Fig. 6).

Eight thousand native English subjects have been surveyed, and five different variants of myoglobin detected, thus indicating that variant myoglobins will be present in the case of myoglobinuria in about 1,600 . Of the variants so far found, two are positively and three are negatively charged, but in each case normal myoglobin was also present in the muscle extract. If such heterozygotes were ever to pass myoglobin into their urine, electrophoresis on the systems recommended here would therefore detect a band of myoglobin in the usual position.

We wish to thank Mr M. V. Braimbridge, Dr J. Liddell, and Dr G. L. Scott for supplying the samples to us.

\section{References}

Allison, A. C. (1965). Population genetics of abnormal haemoglobins and glucose-6 phosphate dehydrogenase deficiency. In Abnormal Haemoglobins in Africa, edited by J. H. P. Jonxis, pp. 365-391. Blackwell, Oxford.

Awad, E., Cameron, B., and Kotite, L. (1963). Chromatographic separation of haemoglobin and myoglobin on 'Sephadex' gel. Nature (Lond.), 198, 1201-1202.

Berenbaum, M. C., Birch, C. A., and Moreland, J. D. (1955). Paroxysmal myoglobinuria. Lancet, 1, 892-896.

Bird, G. W. G., and Lehmann, H. (1956). Haerroglobin D in India. Brit. med. J., 1, 514.
Blondheim, S. H., Margoliash, E., and Shafrir, E. (1958). A simple test for myohemoglobinuria (myoglobinuria). J. Amer. med. Ass., $167,453-454$.

Boulton, F. E., Huntsman, R. G., Lehmann, H., Lorkin, P. A., and Romero-Herrera, A. E. (1970). Myoglobin variants. Biochem. J., 119, 69.

Boulton, F. E., Huntsman, R. G., Yawson, G. I., Romero Herrera, A. E., Lorkin, P. A., and Lehmann, H. (1971). The second variant of human myoglobin; 138 (H16) arginine $\rightarrow$ glutamine. Brit. J. Haemat., 20, 69-74.

Boyer, S. H., Fainer, D. C., and Naughton, M. A. (1963). Myoglobin: inherited structural variation in man. Science, 140, 1228-1231.

Cradock-Watson, J. E., Fenton, J. C. B., and Lehmann, H. (1959). TRIS buffer for the demonstration of haemoglobin A, by paper electrophoresis. J. clin. Path., 12. 372-373.

Craig, L. C., King, T. P., and Stracher, A. (1957). Dialysis studies. II. Some experiments dealing with the problem of selectivity. J. Amer. chem. Soc., 79, 3729-3737.

Duma, R. J., Trigg, J. W., and Hammack, W. J. (1962). Primary myoglobinuria. Ann. intern. Med., 56, 97-104.

Elek, S. D., and Anderson, H. F. (1953). Paroxysmal paralytic myoglobinuria. Brit. med. J., 2, 533-536.

Eliot, R. S., Shafer, R. B., and Gibas, M. A. (1967). Demonstration of myoglobinemia in football players. Arch. phys. Med., 48, 229-232.

Fletcher, W. D., and Prankerd, T. A. J. (1955). Paroxysmal myoglobinuria. Lancet, 1, 1072.

Graham, J. L., and Grunbaum, B. W. (1963). A rapid method for microelectrophoresis and quantitation of hemoglobins on cellulose acetate. Amer. J. clin. Path., 39, 567-578.

Jonxis, J. H. P. (1965). Haemoglobinopathies in West Indian groups of African origin. In Abnormal Haemoglobins in Africa, edited by J. H. P. Jonxis, pp. 329-338. Blackwell, Oxford.

Konigsberg, W., Huntsman, R. G., Wadia, F., and Lehmann, H. (1965). Haemoglobin $D \beta_{\text {Purjab }}$ in an East Anglian family. J. roy. Anthrop. Inst., 95, 295-306.

McArdle, B. (1951). Myopathy due to a defect of muscle glycogen breakdown. Clin. Sci., 10, 13-33.

Marti, H. R., Beale, D., and Lehmann, H. (1967). Haemoglobin Koelliker: A new acquired haemoglobin appearing after severe haemolysis: $a_{2}$ minus 141 Arg $\beta_{2}$. Acta haemat. (Basel), 37, 174-180.

Ornstein, L. (1964). Disc electrophoresis. I. Background and theory. Ann. N.Y. Acad. Sci., 121, 321-349.

Prankerd, T. A. J. (1956). Electrophoretic properties of myoglobin and its character in sickle-cell diseases and paroxysmal myoglobinuria. Brit. J. Haemat., 2, 80-83.

Thomas, P. K. (1968). Diseases of $\mathrm{m} u$ icle. In Recent Advances in Medicine, 15 th ed., edited by D. N. Baron, N. Compston, and A. M. Dawson, pp. 36-61. J. Churchill, London.

Vesterberg, O. (1967). Isoelectric fractionation, analysis, and characterisation of ampholytes in natural $\mathrm{pH}$ gradients. V. Separation of myoglobins and studies on their electro-chemical differences. Acta chem. scand., 21, 206-216.

Whisnant, C. L., Jr., Owings, R. H., Cantrell, C. G., and Cooper, G. R. (1959). Primary idiopathic myoglobinuria in a negro female: its implications and a new method of laboratory diagnosis. Ann. intern. Med., 51, 140-150.

Wrigley, C. W. (1968). Analytical fractionation of plant and animal proteins by gel electrofocusing. J. Chromatogr., 36, 362-365. 